\title{
Electric Field Simulation Around Contaminated SIR Insulators Using MATLAB
}

\author{
G. Satheesh \\ Department of Electrical and \\ Electronics Engineering \\ SR Engineering College \\ Warangal, Telangana, India \\ satheeshtrrec@gmail.com
}

\author{
B. Basavaraja \\ Department of Electrical and \\ Electronics Engineering \\ University B.D.T. College of \\ Engineering, Karnataka, India \\ banakara36@gmail.com
}

\author{
P. M. Nirgude \\ UHV Research Laboratory \\ Central Power Research Institute \\ Telangana, India \\ nirgudepm@yahoo.co.in
}

\begin{abstract}
High voltage insulators are mainly used to support transmission lines. This paper focuses on simulating the electric field along the surface of contaminated Silicone Rubber (SIR) insulators. The electric field (EF) distribution is important to determine the EF stress occurring on the insulator surface. So, the EF distribution is analyzed using a FEM tool in MATLAB under various conditions. Two types of insulators, straight and alternate sheds, were considered. Results showed that higher EF stresses occurs on the trunk portions of both straight shed and alternate shed types. Also, the results showed higher EF magnitude on the straight shed compared to the alternate shed, under both clean and contamination conditions.
\end{abstract}

Keywords-electric field distribution; electric potential; finite element method; silicone rubber insulator; water droplet

\section{INTRODUCTION}

Electrical insulators are electrically insulating components used in various electrical installations. The main aim of this paper is to focus on simulating the electric field (EF) distribution around a silicon rubber (SIR) insulator under various conditions using MATLAB. Insulators may fail when pollutants accumulate on their surface and certain environmental stresses occur [1-8]. These conditions are commonly seen in the field with in-service insulators located near polluting sources like coastal areas and agricultural fields [1-8]. The EF distribution is important to find the electric field stress occurring on the SiR insulator surface under various conditions. Two types of insulators, having straight and alternate sheds were used for analysis of EF along insulators. Up until 1963, the insulator manufacturing industry produced mainly ceramic (glass and porcelain) insulators. But in the recent years, composite (SIR) insulators have gained a large share of the market. Compare to conventional insulators, silicon rubber insulators offer certain obvious advantages such as low weight, but the most significant advantage is related to their hydrophobic surface that allows them to operate fault and maintenance free in polluted areas [1-8]. To analyze the characteristics of SIR insulators, modeling and simulations were done under different contaminated conditions. SIR insulator consists of the FRP core, housing, sheds and metal end fittings. The core of a non-ceramic insulator has the dual burden of being the main insulating part and also of being the main load-bearing member be it in suspension, cantilever or compression modes. Sheds made from various non-ceramic materials are shaped and spaced over the rod in various ways to protect the rod and to provide maximum electrical insulation between the attachment ends (also considering weather patterns). End fitting transmits the mechanical load to the core. They are usually made of metal. The most commonly used housing material for composite insulators is SIR due to its properties related to surface hydrophobicity [1-8]. The effect of contamination on SIR insulator is usually analyzed by placing dust along with droplets on the surface while a voltage source is applied to one end (usually the lower electrode).

\section{FEM}

Four classical methods for solving the partial differential equations (PDE) are the charge simulation method (CSM), the finite difference method (FDM), the boundary element method (BEM) [9] and the finite element method (FEM) [10-12]. Out of these four, FEM has a dominant position because of its strong interchangeability [13-15]. The finite element approach is based on the suggestion of building an elaborate object with easy blocks or dividing an elaborate object into small and manageable pieces. In FEM the area is split right into a finite number of elements. These elements are related at nodes. A suite of linear algebraic equations are to be solved in case of linear issues. Higher precision may also be accomplished by increasing the number of elements and for a discretized problem approximation results in a set of sparse equations. This leads to resolve issues with a number of unknown nodal values.

Finite element methods are enormously versatile and powerful and can permit designers to obtain know-how concerning the electrical stresses taking place on the outside of insulators [14-15]. Regardless of the big advances which were made in establishing finite element applications, the received outcome ought to be cautiously examined before applied in real conditions. Essentially the biggest challenge of finite element methods is that the resolution accuracy is traditionally a function of the mesh decision. Any regions of enormously centered electrical stress have to be carefully analyzed with the usage of a sufficiently sophisticated mesh. Today's finite 
element applications are powerful tools which have come to be more and more indispensible to insulator design and evaluation. However, additionally they make it effortless for users to make errors.

\section{SimULATION RESUlTS}

In this study, clean and contaminated conditions have been simulated with the use of PDE tool in MATLAB. The two dimensions of SIR insulator under contaminated and clean conditions for FEM analysis are shown in Figures 1 and 5. The finite element discretization results are shown in Figures 2 and 6. The simulation result under clean condition is illustrated in Figure 3. Also, the simulation result under contamination conditions are illustrated in Figures 7 and 8. As illustrated in Figures 7 and 8 the dusts along with droplets have the most effect on EF along insulator. In case of straight SIR insulator, situation of contamination is simulated by means of putting dust and 42 drops as shown in Figure 5a. The simulation outcomes are illustrated in Figures $7 \mathrm{a}$ and $7 \mathrm{~b}$ with dust and drops. In step with obtained results, existence of various dusts together with drops would create EF enhancement on insulator. It is also observed that the stresses occuring on the trunk portions of insulator are high compare to other portions of insulator.

In case of an insulator with alternate sheds, condition of contamination is simulated via placing dust and 56 drops as in Figure 5b. The simulation outcomes are illustrated Figures $8 \mathrm{a}$ and $8 \mathrm{~b}$ with dust and drops. According to obtained results, the existence of dust and water drops would create EF enhancement on insulator surface. It is observed that the field stresses occuring on insulator trunks are high compare to other portions of insulator. The results illustrated in Figures 4 and 9 show that the highest EF occur on the trunk portion than shed portion for both straight and alternate shed SIR insulators. The EF stress on insulator of straight shed SIR is higher than the insulator of alternate shed SIR from Table I under clean condition and from Table II under contamination condition. Also EF stress occurring on straight shed SIR insulator is $7 \%$ to $31 \%$ higher than stress occurring on the alternate shed insulator under various conditions.

TABLE I. ELECTRIC FIELD COMPARISON - CLEAN INSULATORS

\begin{tabular}{|c|c|c|c|c|}
\hline \multirow{2}{*}{ S. No. } & \multirow{2}{*}{ Type of Insulator } & \multicolumn{3}{|c|}{ Max. Electric field E (KV/c.m) on insulator } \\
\cline { 3 - 4 } & & \multicolumn{3}{|c|}{ Under Clean Condition } \\
\cline { 3 - 4 } & & Near HV end & Near Ground & Between Sheds \\
\hline 1 & Straight Shed & 2.75 & 2.75 & 1.4 \\
\hline 2 & Alternate Shed & 2.4 & 2.4 & 1.25 \\
\hline
\end{tabular}

TABLE II. ELECTRIC FIELD COMPARISON - POLLUTED INSULATORS

\begin{tabular}{|c|c|c|c|c|c|c|c|}
\hline \multirow{3}{*}{ S. No. } & \multirow{3}{*}{ Type of Insulator } & \multicolumn{6}{|c|}{ Max. Electric field E (KV/c.m) on insulator } \\
\cline { 3 - 8 } & & \multicolumn{2}{|c|}{ With Cement Dust and water drops } & \multicolumn{2}{|c|}{ With Plywood Dust and water drops } \\
\cline { 3 - 8 } & & $\begin{array}{c}\text { Near HV } \\
\text { end }\end{array}$ & $\begin{array}{c}\text { Near } \\
\text { Ground }\end{array}$ & $\begin{array}{c}\text { Between } \\
\text { Sheds }\end{array}$ & $\begin{array}{c}\text { Near HV } \\
\text { end }\end{array}$ & Near Ground & $\begin{array}{c}\text { Between } \\
\text { Sheds }\end{array}$ \\
\hline 1 & Straight Shed & 2.5 & 2.5 & 1.5 & 2.9 & 2.9 & 1.65 \\
\hline 2 & Alternate Shed & 2.35 & 2.35 & 1.2 & 2.2 & 2.0 & 1.35 \\
\hline
\end{tabular}

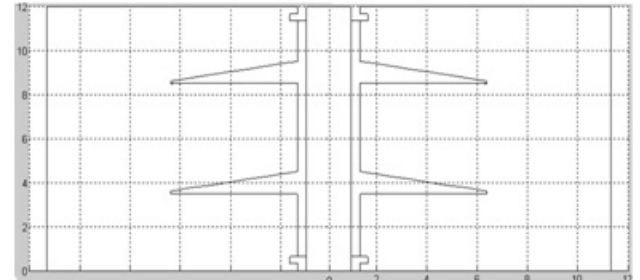

a. Straight shed insulator

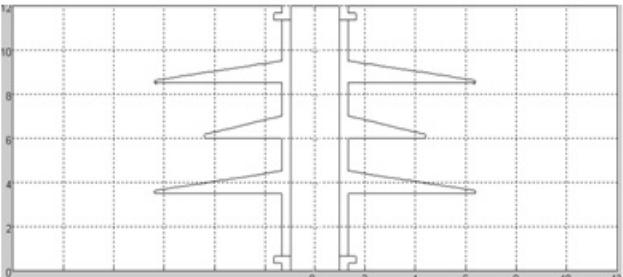

b. Alternate shed insulator

Fig. 1. 2D view of SIR insulator under clean condition for FEM analysis.

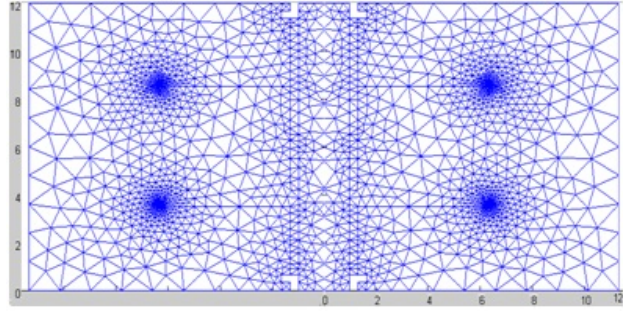

a. Straight shed insulator

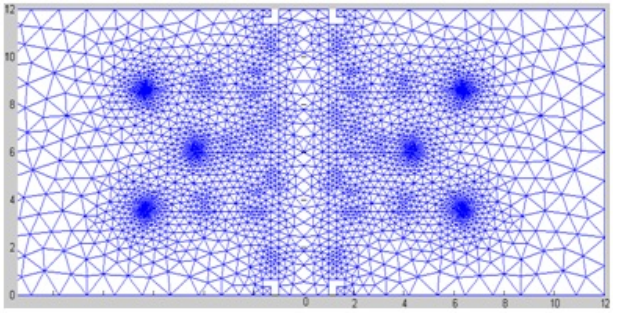

b. Alternate shed insulator

Fig. 2. Discretization results under clean condition for FEM analysis. 


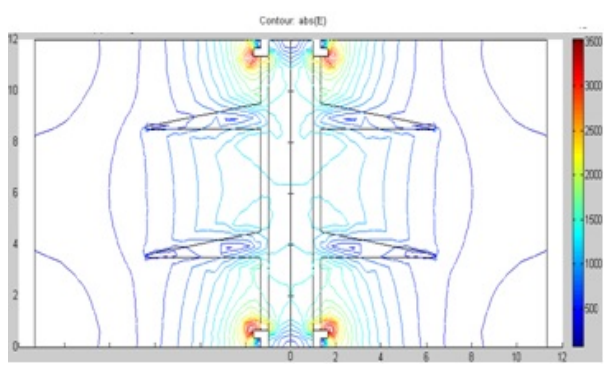

a. Straight shed insulator

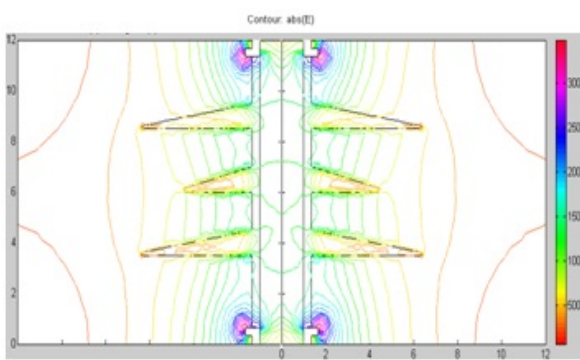

b. Alternate shed insulator

Fig. 3. EF Distribution under clean conditions.

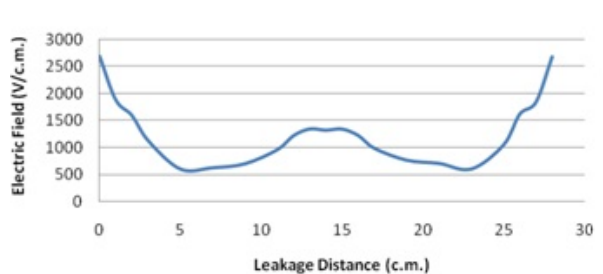

a. Straight shed insulator

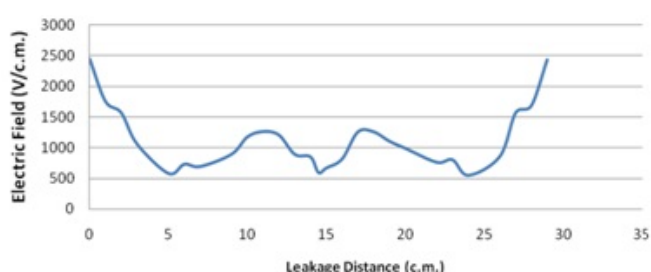

b. Alternate shed insulator

Fig. 4. EF along insulator under clean conditions.

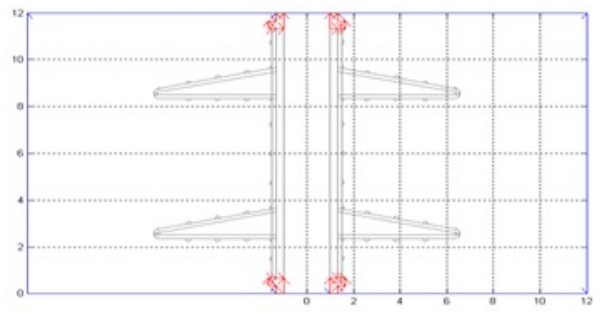

a. Straight shed insulator

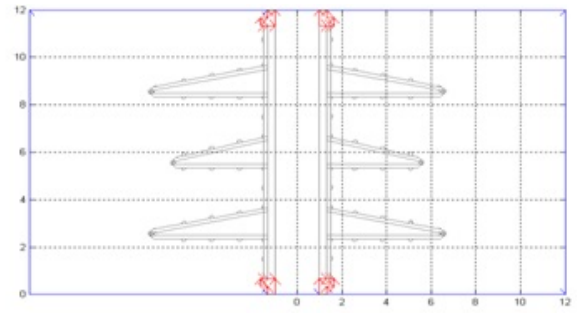

b. Alternate shed insulator

Fig. 5. 2D view of SIR insulator under contamination condition for FEM analysis.

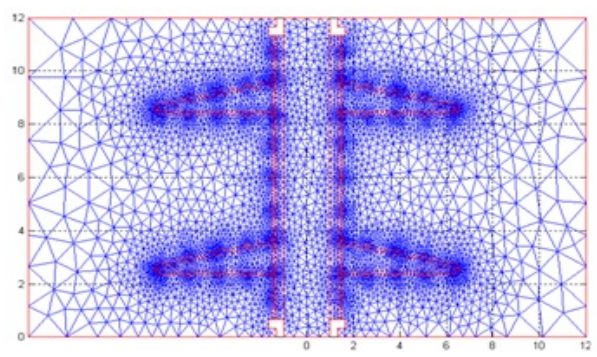

a. Straight shed insulator

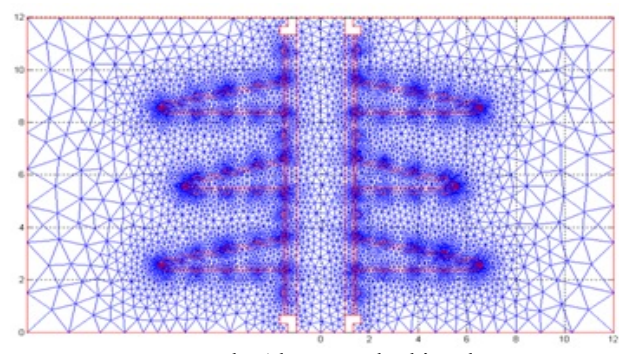

b. Alternate shed insulator

Fig. 6. Discretization results under contamination condition for FEM analysis.

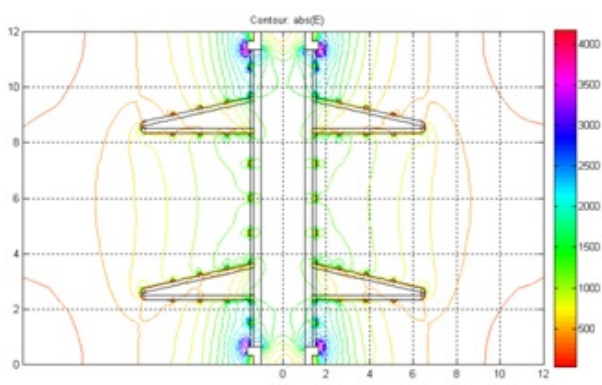

a. Cement dust and drops

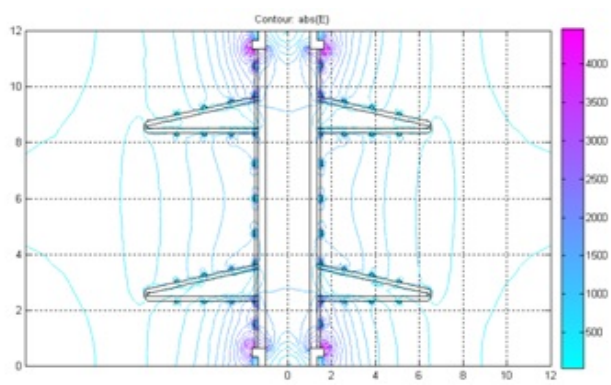

b. Plywood dust and drops

Fig. 7. Electric Field along straight shed SIR insulator considering contamination. 


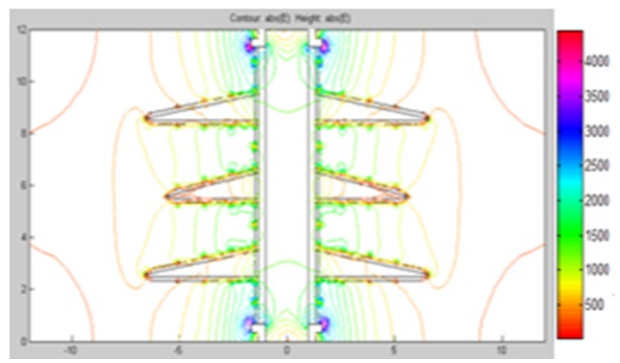

a. Cement dust and drops

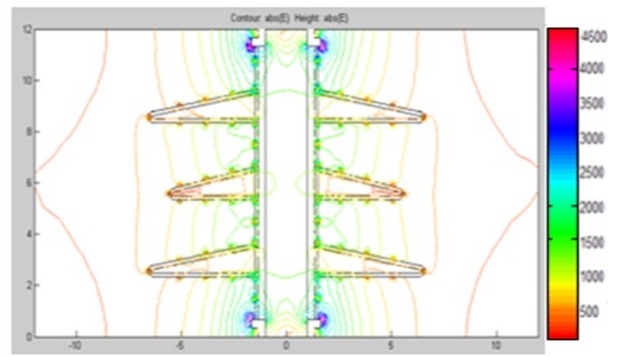

b. Plywood dust and drops

Fig. 8. Electric Field along alternate shed SIR insulator considering contamination.

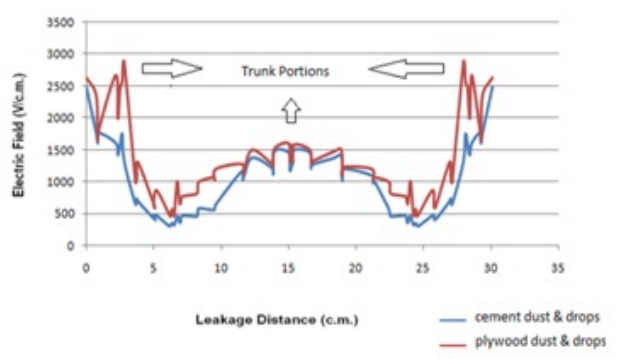

a. Straight shed insulator

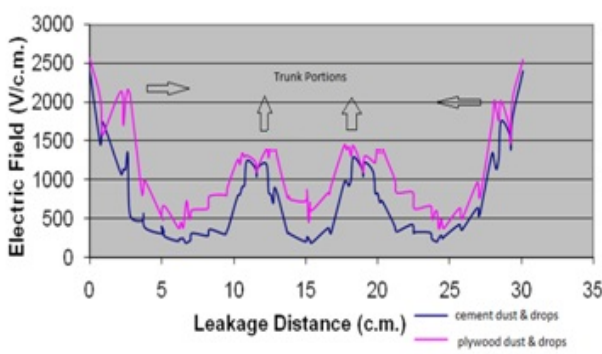

b. Alternate shed insulator

Fig. 9. Electric Field along insulator under contamination.

\section{CONCLUSION}

In this paper, EF distributions were investigated by using a PDE tool in MATLAB to simulate clean and polluted SIR insulators of two types: straight and alternate shed. According to the obtained results, higher EF stresses occur on the trunks of both straight and alternate shed SIR insulators and EF stress also depends on the pollutants. Higher EF is computed in the case of straight shed insulators ( $7 \%$ to $31 \%$ higher).

\section{REFERENCES}

[1] K. O. Papailiou, F. Schmuck, Silicone Composite Insulators. Materials, Design, Applications, Springer, 2013

[2] CIGRE TF 33.04.01, Polluted insulators: a review of current knowledge, CIGRE, 2000

[3] K. Chrzan, Z. Pohl, T. Kowalak, "Hygroscopic Properties of Pollutants on HV Insulators", IEEE Transactions on Electrical Insulation, Vol. 24, No. 1, pp. 107-112, 1989

[4] N. Mavrikakis, E. Koudoumas, K. Siderakis, D. Pylarinos, E Thalassinakis, O. Kokkinaki, A. Klini, C. Kalpouzos, M. Polychronaki, D. Anglos, "Insulators' pollution problem: Experience from the coastal transmission system of Crete", 52nd International Universities' Power Engineering Conference (UPEC 2017), Heraklion, Crete, August 29September 1, 2017

[5] K. Siderakis, D. Pylarinos, E. Thalassinakis, I. Vitellas, E. Pyrgioti, "Pollution maintenance techniques in coastal high voltage installations", Engineering Technology and Applied Science Research, Vol. 1, No. 1, pp. 1-7, 2011

[6] D. Pylarinos, K. Siderakis, E. Thalassinakis, "Comparative Investigation of Silicone Rubber Composite and RTV Coated Glass Insulators Installed in Coastal Overhead Transmission Lines", IEEE Electrical Insulation Magazine, Vol. 31, No. 2, pp. 23-29, 2015
[7] M. Dimitropoulou, D. Pylarinos, K. Siderakis, E. Thalassinakis, M. Danikas, "Comparative Pollution Field Measurements on Outdoor Insulators of Different Material and Design", Engineering, Technology \& Applied Science Research, Vol. 5, No. 2, pp. 764-774, 2015

[8] D. Pylarinos, K. Siderakis, E. Koudoumas, E. Thalassinakis, "Polymer Insulators and Coatings in the Cretan Power System. The Transmission Line Case", 9th Mediterranean Conference on Power Generation, Transmission Distribution and Energy Conversion, Athens, Greece, 2-5 November, 2014

[9] K. Eldridge, J. Xu, W. Yin, A. M. Jeffery, J. Ronzello, S. A. Boggs, "Degradation of a Silicone based coating in a substation application", IEEE Transactions on Power Delivery, Vol. 14, No. 1, pp. 188-193, 1999

[10] H. Singer, F. Gutfleisch, K. Forger, J. A. Gomollon, "Calculation of high-voltage fields by means of boundary element method", IEEE Transactions on Power Delivery, Vol. 9, No. 2, pp. 743-749, 1994

[11] M. V. K. Chari, G. Bedrosian, J. D. Angelo, "Finite element applications in electrical engineering", IEEE Transactions on Magnetics, Vol. 29, No. 2, pp. 1306-1314, 1993

[12] C. R. I. Emson, J. Simkin, C. W. Trowbridge, "A status report on electromagnetic field computation", IEEE Transactions on Magnetics, Vol. 30, No. 4, pp. 1533-1540, 1994

[13] V. T. Kontargyri, I. F. Gonos, I. A. Stathopulos, "Measurement and Simulation of electric field of high voltage suspension insulators", European Transactions on Electrical Power, Vol. 19, pp. 509-517, 2008

[14] W. Sima, Q. Yang, C. Sun, F. Guo, "Potential and electric-field calculation along an ice-covered composite insulator with finite-element method", IEE Proceedings-generation Transmission and Distribution, Vol. 153, No. 3, pp. 343-349, 2006

[15] U. Van Rienen, M. Clemens, T. Wieland, "Simulation of low-frequency fields on high-voltage insulators with light contaminations", IEEE Transactions on Magnetics, Vol. 32, No. 3, pp. 816-819, 1996 